\title{
Effect of grammar intervention on vocabulary skills in children with a cochlear implant: A single-subject study
}

\author{
Nasibe Soltaninejad ${ }^{1}$, Nahid Jalilevand ${ }^{1,2}$, Mohammad Kamali ${ }^{2,3^{*}} \mathbb{D}$, Reyhane Mohamadi $^{1,2}$ \\ Received: 4 Mar 2020 \\ Published: 29 Sep 2021
}

\section{Abstract}

Background: Previous studies have shown that children with cochlear implants have difficulty in grammar acquisition. Vocabulary acquisition and grammar abilities are important during language development. The purpose of this studly was to investigate the effect of grammar therapy on the lexical ability of cochlear implanted children.

Methods: Five children with cochlear implants and grammatical problems were treated using a grammar task designed for the current study. Before and after the treatment, repeated evaluations were performed using the Mean Length of Utterance (MLU) and Persian Developmental Sentence Scoring (PDSS) indices for grammar and NDW and NTW indices for vocabulary abilities; these show the number of different words and the number of total words respectively.

Results: Grammar intervention was successful in cochlear implanted children of the present study. In addition, treatment of grammatical problems increased the lexical ability of all children; NDW and NTW scores increased, which was confirmed by the effect size indices. In the follow-up phase, the cochlear implanted children were able to maintain the increase in NTW and NDW values.

Conclusion: Improving grammar skills in cochlear implanted children also increased their lexical ability. Therefore, grammar therapy helps to increase the vocabulary of children too.

Keywords: Grammar, Lexical Ability, Children, Cochlear Implant, Language Therapy

Conflicts of Interest: None declared

Funding: Iran University of Medical Sciences (code of ethics: 1396.9321363001).

\section{*This work has been published under CC BY-NC-SA 1.0 license.}

Copyright $\odot$ Iran University of Medical Sciences

Cite this article as: Soltaninejad N, Jalilevand N, Kamali M, Mohamadi R. Effect of grammar intervention on vıcabulary skills in children with a cochlear implant: A single-subject study. Med J Islam Repub Iran. 2021 (29 Sep);35:126. https://doi.org/10.47176/mjiiri.35.126

\section{Introduction}

Cochlear implantation in children with severe to profound hearing loss has the advantage of achieving auditory comprehension and speech production. Improving language skills is an important goal after cochlear implantation $(1,2)$. Furthermore, the age at which these children receive cochlear implants is an important factor in achieving this goal (3-5). Children who do not receive cochlear

Corresponding author: Dr Mohammad Kamali, kamali.mo@iums.ac.ir

1. Department of Speech and Language Pathology, School of Rehabilitation Sciences, Iran University of Medical Sciences, Tehran, Iran

2. Rehabilitation research center, Iran University of Medical Sciences, Tehran, Iran

3. Department of Rehabilitation Management, School of Rehabilitation Sciences, Iran University of Medical Sciences, Tehran, Iran implants at the appropriate age have difficulty in learning vocabulary and grammar (6). Children with hearing loss who have experienced the reinforcement of cochlear implants performs better in different aspects of language, like vocabulary, syntax, and morphology (7). Although cochlear implantation is an important factor in acquiring age-appropriate language skills, Monteir et al. in their

\section{$\uparrow$ What is "already known" in this topic:}

Cochlear implantation helps deaf children to acquire language skills but they don't have similar abilities to learn different aspects of the language. Studies have demonstrated that children with cochlear implants have difficulties in grammar acquisition.

\section{$\rightarrow$ What this article adds:}

The current single-subject study found that grammar treatment improves the morphosyntax ability of children with cochlear implants. Moreover, grammar treatment improved their lexical abilities. Therefore, grammar therapy helps to increase the vocabulary of children too. 
study, showed that cochlear implanted children had delayed language development compared to their normalhearing peers (8). In various studies, such as those by Hayes et al. and Valimaa et al., it was shown that cochlear implanted children have a delay in receptive and expressive vocabulary compared to children with normal hearing $(9,10)$. Hammer et al. in their study, stated that less than $50 \%$ of children with cochlear implants achieve the ability to use grammatical morphemes that are appropriate to their age (11). According to the study of Colatto et al., the lexical ability of cochlear implanted children depends on a variety of factors, such as the age at which cochlear implants are received, the age of hearing, and, significantly, the role of parents in the process of rehabilitation (12). Mederak's study of the impact of early intervention on speech and language development showed that children who are implanted younger than two years of age behave similar to and sometimes better than their normal peers in terms of grammar (13). Tavakoli et al. concluded that the syntactic complexity of speech of cochlear implanted children was lower than normal-hearing children (14). Golestani et al., in their study, showed that the Persian Developmental Sentence Scoring (PDSS) of five-year-old cochlear implanted children was significantly lower than normal-hearing children of the same age (15). Cochlear implantation is effective in the treatment of language deficits in hearing-impaired children when it comes to speech therapy (8), and therapists who work with cochlear implanted children should be aware that they should not only emphasize the single word level but also they should consider intervention at the level of the combining word that leads to better results in treatment. There are two hypotheses for the development of grammatical and lexical systems: The first is domain-specificity, which states that different linguistic domains grow separately; for example, there are two separate systems for vocabulary and grammar development (16). The second and contrary hypothesis is that the domain-generality hypothesis, which indicates that there are connections between different domains of the language, for example, vocabulary and grammar, have the same cognitive origin $(17,18)$. The second hypothesis is supported by studies showing that there is a relationship between vocabulary size and grammar. Moyle et al. in their study, concluded that grammar and lexical development are strongly related (19). This hypothesis has also been investigated in children with language disorders. In the case of cochlear implanted children, the study of Jung and Ertmer showed that, in both cochlear implanted children and those children with normal hearing, grammatical skills are closely related to their vocabulary skills. This correlation was very high for cochlear implanted children (20).

Based on this hypothesis, it is expected that if a cochlear implanted child has grammatical problems, these problems are treated, and if this treatment improves the child's grammar problems, this improvement will also increase the child's vocabulary skills. This hypothesis was then investigated in the present study. We used a researchermade grammar therapy program based on the normal development of the Persian language for the treatment of grammar in five cochlear implanted children. This program was used because deaf children who receive cochlear implants have the ability to speak normally if they have normal cognitive skills (21).

We used two indices to measure children's grammar ability before and after the treatment of grammar: PDSS, which shows morpho-syntactic skills of Persian children (22), and MLU which represents syntax abilities of children (23). Two indices also assessed lexical ability: Number of Different Words (NDW), which evaluates an aspect of vocabulary development (19); and Number of Total Words (NTW) that specifies the total number of words used by the child. In this study, the following question will be answered in the present article: Can grammar therapy improve the lexical ability of cochlear implanted children?

\section{Methods \\ Participant}

Thirty cochlear implanted children referred to Shafa hospital in Kerman were selected according to the inclusion criteria. Inclusion criteria included the following: according to their speech samples, they had at least 50 clear utterances and; there were grammatical problems in their speech samples; they had no history of brain damage and hearing problems such as infection in the middle ear, they had no structural or motor problems in their speech organs that were examined by the Robbins-Klee assessment form (24); and according to the ling test (25) and examinations performed by an audiologist, their devices were working properly. Twenty-five children were excluded from the study for the following reasons: 12 of them because of being in speech therapy sessions at other centers; eight of them because of unwillingness to participate in the study and the long distance from the center; three of them due to having parental hearing problems; and two of them due to bilingualism. In this way, five cochlear implanted children, including three boys and two girls, were included. Table 1 shows the characteristics of the participants.

\section{Study design}

This study was a single-subject study that employed an ABA design. The grammar intervention program created in the present study was performed on each child. Initially, they were evaluated for four weeks at the end of each week without any treatment program (four sessions), and their speech samples were analyzed. Then they were treated with the grammar program for approximately 10 weeks, with two sessions per week (20 sessions). During this period, their speech samples were collected and evaluated every two weeks (five sessions). After that, the children had no treatment for four weeks and their speech samples were evaluated weekly (four sessions). The three phases of treatment in the present study are illustrated in Figure 1.

Specifications of the research-made grammar treatment program: Based on the normal development of language in two- to five-year-old children, the grammatical components used by them were extracted. Since the training of 


\begin{tabular}{|c|c|c|c|c|c|c|}
\hline Child & Side of CI use & Gender & $\begin{array}{l}\text { Age of implantation } \\
\text { (Months) }\end{array}$ & $\begin{array}{c}\text { Chronological age } \\
\text { (Months) }\end{array}$ & $\begin{array}{c}\text { Type \& Severity of } \\
\text { hearing loss }\end{array}$ & $\begin{array}{c}\text { Duration of CI use } \\
\text { (Months) }\end{array}$ \\
\hline 1 & Right & Boy & 29 & 80 & $\begin{array}{c}\text { Congenital } \\
\text { bilateral \& profound }\end{array}$ & 51 \\
\hline 2 & Right & Boy & 26 & 86 & $\begin{array}{l}\text { Congenital } \\
\text { bilateral \& profound }\end{array}$ & 60 \\
\hline 3 & Right & Girl & 25 & 60 & $\begin{array}{l}\text { Congenital } \\
\text { bilateral \& profound }\end{array}$ & 35 \\
\hline 4 & Right & Boy & 31 & 81 & $\begin{array}{l}\text { Congenital } \\
\text { bilateral \& profound }\end{array}$ & 50 \\
\hline 5 & Right & Girl & 36 & 99 & $\begin{array}{l}\text { Congenital } \\
\text { bilateral \& profound }\end{array}$ & 63 \\
\hline
\end{tabular}

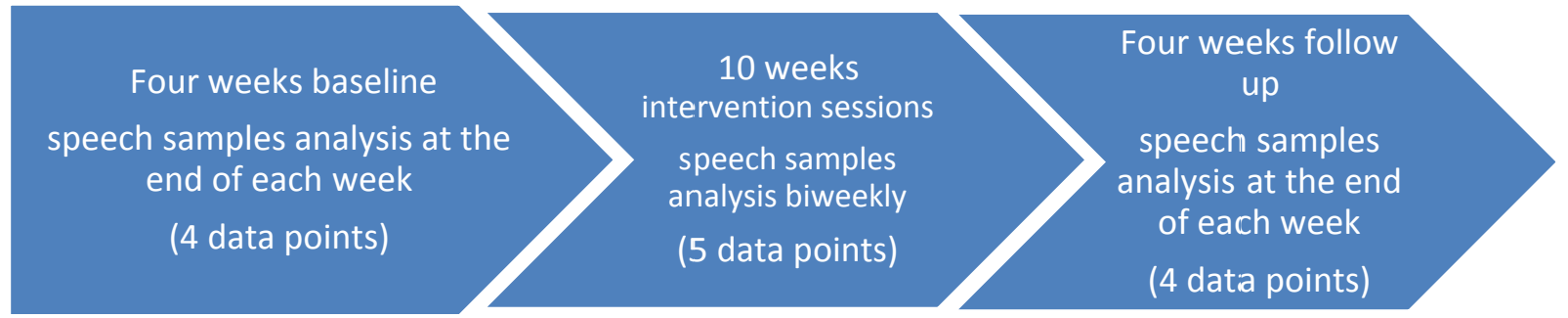

Fig. 1. The three phases of treatment

grammatical components was based on a sentence for each of the grammatical components, several sentences were constructed that had the following characteristics: using basic vocabulary in them (26); using patterns of word order in Persian children's sentences (27); and using different grammatical roles of grammatical components (subject, object) in constructing sentences. The sentences were arranged from simple to complex in terms of length and grammatical complexity.

\section{Collection of speech (language) samples}

Language samples of children were taken by a speech therapist using pictures and toys. In this way, at least 50 utterances were taken from each child in 30 minutes. Language samples were recorded to extract grammatical components and PDSS, MLU, NDW and, NTW indices.

\section{Intervention process}

Grammar intervention was performed by a speech therapist working in the field of language disorders. The grammatical components that the children did not use, but based on the normal development of grammar should be presented in their speech, were selected for the treatment. The therapeutic techniques used by the speech therapist included imitation, partial imitation, modeling and, recasting. The treatment of each grammatical component ended when the child could produce it spontaneously. The speech therapists have used tools such as pictures, toys, and animations to treat grammatical components.

\section{Data analysis}

ccording to the NDW and NTW diagrams in baseline, intervention, and follow-up phases, we used visual analysis of data. In addition, two indices including Percentage of Non-overlapping Data (PND) and Improvement Rate Difference (IRD), which are correlated with visual analy- sis (28), were used. The effect size indices show the effectiveness of intervention by treatment protocols in each individual (29). PND and IRD were also calculated for MLU and PDSS to determine the efficacy of the grammar treatment.

\section{Results}

The grammatical components that were selected for treatment and the children able to use them after treatment in their speech are listed in Table 2.

According to Table 2, the grammatical components taught to children consisted of verbs, pronouns, and conjunctions: six verbs, eight pronouns, and three conjunctions including six bound morphemes (26/086\%) and 17 $(73 / 913 \%)$ free morphemes, so, in total, 23 free and bound morphemes $(100 \%)$.

$M L U$ and PDSS: During the baseline, treatment, and follow-up phases, children's language samples were recorded and analyzed. All five children used the trained grammatical components in the speech sample. MLU and the PDSS before and after treatment, which show the success of grammar therapy (the first and ninth assessment sessions, and the mean of these two indices in the baseline and intervention phases), are presented in Tables 3 and 4.

As depicted in Tables 3 and 4, MLU and PDSS increased in all children at the end of treatment. The values of PND and IRD in Table 5 confirm these increases.

$N D W$ and NTW: A total of 13 data points were obtained, and NDW and NTW were examined. The NDW of the children's speech (the first and ninth assessment sessions and the mean of these two indices in the baseline and intervention phases) are shown in Table 6.

According to this table, the NDW in five children increased at the last treatment session in the intervention phase compared to the first evaluation session in the baseline phase. The mean of this index also increased during 
Table 2. The grammatical components used by children after grammar treatment

\begin{tabular}{|c|c|}
\hline Child & Grammatical components \\
\hline 1 & $\begin{array}{l}\text { demonstrative pronoun / } \mathrm{Pin} / \text { (means this), linking verb / } \mathrm{Pæst} / \text { (means is), personal pronoun /mæm/ (means I), } \\
\text { verbs with prefixes: /mi/ and /be/ (present tense) like /mixam/ (means I want) and /beræm/ (means I go) }\end{array}$ \\
\hline 2 & $\begin{array}{l}\text { compound sentences with conjunction } / \mathrm{væ} / \text { (means and), verb with prefix /mi/ (past tense) like /mixastæm/ } \\
\text { (means I wanted) /mixast/ (means she/he wanted/, reflexive pronoun /xodet/ (means yourself) }\end{array}$ \\
\hline 3 & $\begin{array}{l}\text { demonstrative pronoun /Pinha/ (means these), common pronoun / mal / (means mine, yours, hers .... which used } \\
\text { for ownership) }\end{array}$ \\
\hline 4 & demonstrative pronoun / $\mathrm{Pin} /, / \mathrm{Ran} /$ (means that), verbs with prefixes /mi/ and /be/ (present tense) \\
\hline 5 & conjunctions /væqtike/ and /bærayePinke/ (mean when and because), indefinite pronoun /hæmin/ (means this) \\
\hline
\end{tabular}

Table 3. MLUm values in baseline and intervention phase

\begin{tabular}{lcccc}
\hline & \multicolumn{2}{c}{ MLU in the baseline phase } & \multicolumn{2}{c}{ MLU in the intervention phase } \\
\hline Child & Datapoint 1 & Mean (SD) & Datapoint 9 & Mean (SD) \\
\hline 1 & 3.01 & $3.07(0.09)$ & 5.34 & $4.96(0.78)$ \\
2 & 6.84 & $7.06(0.16)$ & 8.03 & $7.86(0.29)$ \\
3 & 4.05 & $4.09(0.28)$ & 5.90 & $5.69(0.24)$ \\
4 & 3.21 & $3.27(0.27)$ & 5.54 & $5.49(0.11)$ \\
5 & 7.57 & $7.61(0.03)$ & 8.34 & $8.07(0.27)$ \\
\hline \multicolumn{2}{l}{ MLUm= Mean length of utterance in morpheme }
\end{tabular}

MLUm= Mean length of utterance in morpheme

Table 4. PDSS values in baseline and intervention phase

\begin{tabular}{lcccc}
\hline & \multicolumn{2}{c}{ PDSS in the baseline phase } & \multicolumn{2}{c}{ PDSS in the intervention phase } \\
\hline Child & Datapoint 1 & Mean (SD) & Datapoint 9 & Mean ((SD) \\
1 & 6.61 & $6.54(0.04)$ & 9.03 & $1.72(0.90)$ \\
2 & 9.72 & $9.79(0.09)$ & 12.01 & $11.74(10.79)$ \\
3 & 6.70 & $6.68(0.02)$ & 8.98 & $8.50(0.33)$ \\
4 & 7.19 & $7.16(0.07)$ & 9.21 & $9.18(0.04)$ \\
5 & 10.01 & $9.79(0.17)$ & 11.72 & $10.97(10.88)$ \\
\hline
\end{tabular}

PDSS $=$ Persian developmental sentence scoring

Table 5. Percentage of Non-overlapping Data (PND) \& Improvement Rate Difference (IRD) of PDSS \& MLU in five participants

\begin{tabular}{lcccc}
\hline \multicolumn{3}{c}{} & \multicolumn{2}{c}{ MLU } \\
\hline Child & PNDS & IRD & PND & IRD \\
1 & 80 & 0.775 & 80 & 0.775 \\
2 & 80 & 0.775 & 80 & 0.775 \\
3 & 100 & 1 & 100 & 1 \\
4 & 100 & 1 & 100 & 1 \\
5 & 60 & 0.55 & 80 & 0.775 \\
\hline
\end{tabular}

Table 6. NDW values in baseline and intervention phase

\begin{tabular}{|c|c|c|c|c|}
\hline \multirow[b]{2}{*}{ Child } & \multicolumn{2}{|c|}{ NDW in the baseline phase } & \multicolumn{2}{|c|}{ NDW in the intervention phase } \\
\hline & Datapoint 1 & Mean (SD) & Datapoint 9 & Mean (SD) \\
\hline 1 & 16 & $15.25(0.957)$ & 23 & $20.60(1.816)$ \\
\hline 2 & 41 & $42.75(1.707)$ & 84 & $61.00(15.524)$ \\
\hline 3 & 16 & $14.75(1.892)$ & 22 & $20.20(1.483)$ \\
\hline 4 & 21 & $21.25(0.500)$ & 32 & $27.80(3.346)$ \\
\hline 5 & 20 & $18.75(1.892)$ & 28 & $23.80(2.683)$ \\
\hline
\end{tabular}

the intervention phase compared to the baseline phase. The NTW of the children's speech samples is presented in Table 7 (the first and ninth assessment sessions, and the mean of these two indices in the baseline and intervention phases).
According to the Table 7 , the number of total words used by five children increased in the final session of the intervention phase compared to the first session of the baseline phase. This increase was observed in the mean of total treatment sessions compared to baseline phase ses-

Table 7. NTW values in baseline and intervention phase

\begin{tabular}{|c|c|c|c|c|}
\hline \multirow[b]{2}{*}{ Child } & \multicolumn{2}{|c|}{ NTW in the baseline phase } & \multicolumn{2}{|c|}{ NTW in the intervention phase } \\
\hline & Datapoint 1 & Mean (SD) & Datapoint 9 & Mean $(\mathrm{SD})$ \\
\hline 1 & 100 & $98.25(2.362)$ & 122 & $117.80(3.346)$ \\
\hline 2 & 116 & $115.75(0.957)$ & 227 & $179.00(38.072)$ \\
\hline 3 & 100 & $99.75(2.629)$ & 112 & $106.60(4.393)$ \\
\hline 4 & 115 & $114.25(1.707)$ & 127 & $121.60(4.505)$ \\
\hline 5 & 108 & $105.50(2.645)$ & 120 & $115.40(3.209)$ \\
\hline
\end{tabular}




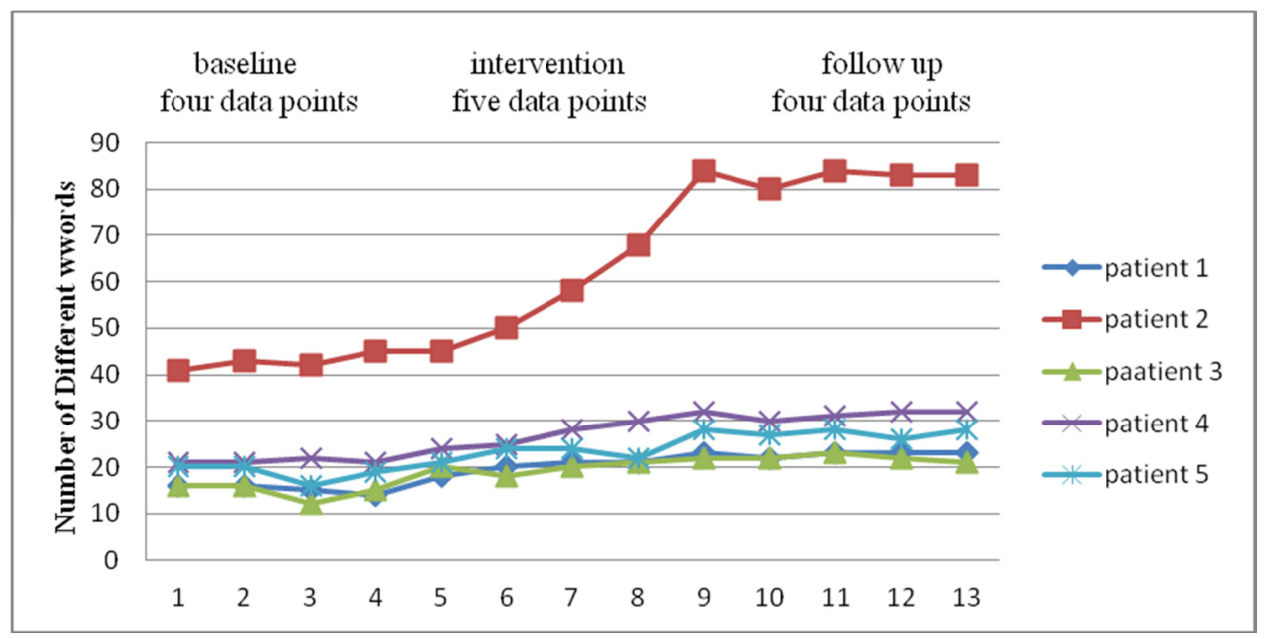

Fig. 2. NDW for five children in three phases of the study

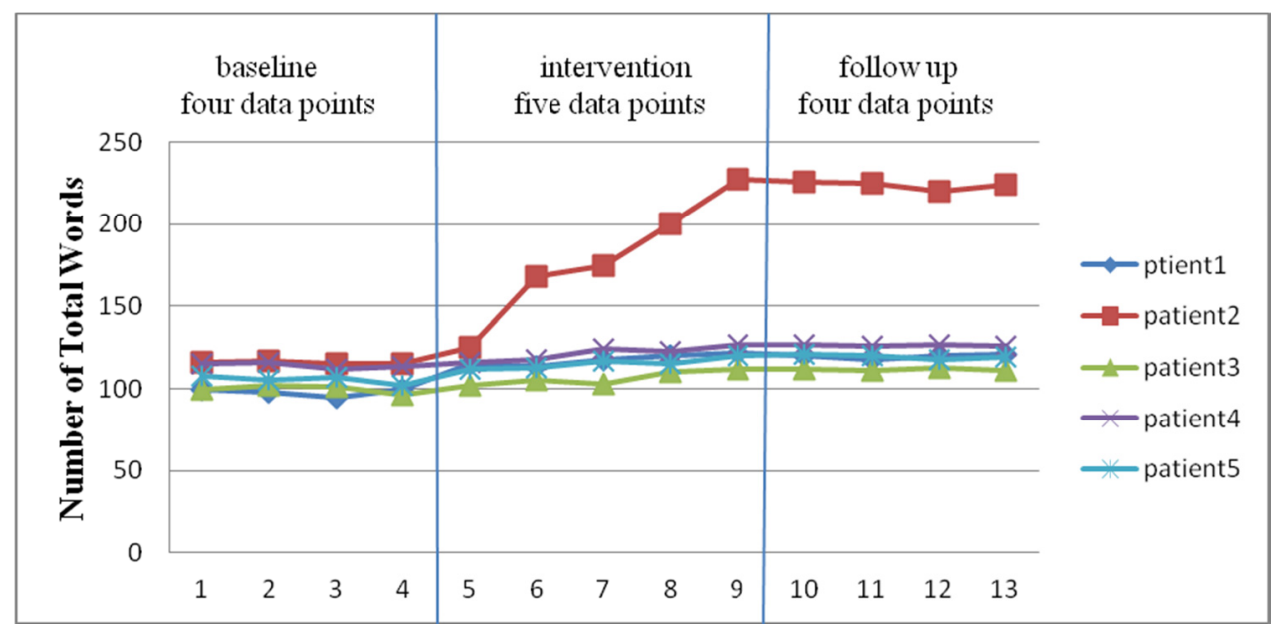

Fig. 3. NTW for five children in three phases of the study

Table 8. Percentage of non-overlapping data\& improvement rate difference of NDW and NTW in five participants

\begin{tabular}{|c|c|c|c|c|}
\hline & \multicolumn{2}{|c|}{ NDW } & \multicolumn{2}{|c|}{ NTW } \\
\hline Child & PND & IRD & PND & IRD \\
\hline 1 & 100 & 1 & 100 & 1 \\
\hline 2 & 80 & 0.775 & 100 & 1 \\
\hline 3 & 100 & 1 & 100 & 1 \\
\hline 4 & 100 & 1 & 100 & 1 \\
\hline 5 & 100 & 1 & 100 & 1 \\
\hline
\end{tabular}

sions. NDW in each of the baseline, intervention, and follow-up phase sessions is also shown in Figure 2.

As is shown in the figure, the NDW used by all the children during the intervention phase is higher than that used in the baseline phase, which indicates an increase in this index after treatment. During the follow-up phase, this increase remains constant. Figure 3 shows the amount of NTW during the three different phases of the study.

According to the figure, in all five children, the increase in the number of total words during the intervention phase compared to the baseline phase and its stability in the follow-up period is evident.

Effect sizes indices: The values of PND and IRD for NDW and NTW are shown in Table 8.

\section{Discussion}

In the present study, the cochlear implanted children were treated with a grammar treatment program made by researchers based on the normal development of grammar in normal Persian- speaking children and then their lexical abilities were measured by NDW and NTW to investigate the impact of grammar treatment on vocabulary ability. Grammatical and lexical skills of cochlear implanted children are delayed compared to normal children. As is shown in the study by Nittrouer et al., cochlear implanted children had significantly lower levels of performance in terms of grammatical and lexical skills than children with normal hearing (30). In our study, treatment was based on the normal development of grammar. Because cochlear implanted children are delayed in language development

http://mjiri.iums.ac.ir

Med J Islam Repub Iran. 2021 (29 Sep); 35.126. 
compared to normal children and on the basis of natural growth, they begin to compensate for the delay. As Golestani et al. showed in their study, children with cochlear implantation and normal-hearing children with identical hearing ages had the same PDSS (15). This result indicates that deaf children begin to compensate for the delay in language after cochlear implantation and that treatment based on normal development is the best form of treatment

In the present study, according to the values obtained from the second phase of the study, improving grammar skills improved vocabulary skills. NDW and NTW of cochlear implanted children increased after grammar treatment, visual analysis, and PND values (\%80 for children No 2, \%100 for No 1, 3, 4 and 5 in case of NDW and $\% 100$ for all children in case of NTW) confirm the changes through treatment. These findings conformed to those of previous studies. Moyel et al. and McGregor et al. in their studies, showed that there is a relationship between children's grammar and lexical abilities $(19,31)$. Jung and Ertmer's study showed that there is a clear relationship between grammatical and lexical abilities in cochlear implanted children (20). In our study, this relationship was demonstrated and confirmed in another way; grammar therapy was successful, MLU and PDSS increased after treatment in all five children, and this success resulted in an increase of the NDW and total words of cochlear implanted children without any treatment for their vocabulary. So, there is a connection between vocabulary development and grammar development, which is justified by the domain-generality hypothesis that states grammar and lexical development have the same cognitive origin.

After grammar treatment, both NDW and NTW increased in all five children, but these increases are more pronounced for the total number of words. This may be due to the fact that in the treatment of these children, the number of free morphemes was higher than the number of bound morphemes. So free morphemes have increased the total number of words but have less effect on the NDW. In our study, there were eight pronouns and three conjunctions that were only applicable in one form, and only verbs had the ability to be used in different forms depending on their prefix.

In the follow-up phase, according to the visual analysis, in all five cochlear implanted children, after treatment based on NDW and NTW indices, with regards to the trend direction, scores remained constant compared to the final session of the treatment phase. No further changes were observed in NDW and NTW during this phase, so it seems cochlear implanted children have been able to keep up the increase in the number of different and total words.

One of the limitations of this study was finding cochlear implanted children who did not go to other speech therapy centers. So we had to contact a lot of families to find these children. Secondly, in some cases, the long distance from the treatment center prevented some families from attending our study. Therefore, a limited number of cochlear implanted children entered the study. Another limitation is that the study is single-subject, which may not apply to all cochlear implants. The third limitation is that, in this study, the effect of grammar treatment on vocabulary was investigated; however, the impact of vocabulary therapy on increasing grammatical ability should also be considered in future studies.

\section{Conclusion}

Grammar training is essential for cochlear implanted children. The current single-subject study found that grammar treatment improves the morphosyntax ability of children with cochlear implants. Moreover, grammar treatment improved their lexical abilities. Therefore, grammar therapy helps to increase the vocabulary of children too.

\section{Acknowledgment}

This study is taken from the Ph.D. thesis of the first author and has been supported financially by Iran University of Medical Sciences (code of ethics: 1396.9321363001).

\section{Conflict of Interests}

The authors declare that they have no competing interests.

\section{References}

1. Nicholas JG, Geers AE. Sensitivity of expressive linguistic domains to surgery age and audibility of speech in preschoolers with cochlear implant. Cochlear Implants int. 2018;19(1):26-37.

2. Svirsky MA, Stallings, LM, Lento CL, Ying E, Leonard LB. Grammatical Morphologic Development in Pediatric Cochlear implant users may be affected by the perceptual prominence of the relevant markers. J Ann Otol Rhinol Laryngol. 2002;3(5):109-112.

3. Nicholas JG, Geers AE. Will they catch up? The role of age at cochlear implantation in the spoken language development of children with severe-profound hearing loss. J Speech Lang Hear Res. 2007;50(4):1048-1062.

4. Dunn CC, Walker EA, Oleson J, Kenworthy M, Voorstb TV, Tomblin $\mathrm{B}$, et al. Longitudinal speech perception and language performance in pediatric cochlear implant users: the effect of age at implantation. J Ear Hear. 2014;35(2):148-160.

5. Svirsky MA, Teosh SW, Neuburger H. Development of language and speech perception in congenitally, profoundly deaf children as a function of age at cochlear implantation. Audiol Neurootol. 2004;9(4):224-233

6. Levine D, Strother-Garcia K, Golinkoff RM, Hirsh-Pasek K. Language development in the first year of life: what deaf children might be missing before cochlear implantation. Otol Neurotol. 2016;37(2):56-62.

7. Nicholas JG, Geers AE. Sensitivity of expressive linguistic domains to surgery age and audibility of speech in preschoolers with cochlear implants. Cochlear implant Int. 2018;19(1):26-37.

8. Monteiro CG, Cordeiro AA, Silva HJ, Queiroga BA. Children's language development after cochlear implantation: a literature review. Codas. 2016;28(3):319-325.

9. Hayes H, Geers AE, Treiman R, Moog JS. Receptive vocabulary development in deaf children with cochlear implants: achievement in an intensive auditory-oral educational setting. Ear Hear. 2009;30(1):128-135.

10. Valimaa T, Kunnari S, Nevala PL, Lonka E. Early vocabulary development in children with bilateral cochlear implants. Int J Lang Commun Disord. 2018;53(1):3-15.

11. Hammer A, Coene M, Rooryck J, Govaerts P. The production of Dutch finite verb morphology: A comparison between hearingimpaired CI children and specific language impaired children. Lingua. 2014;139:68-79.

12. Colatto CA, Goffi-Gomez MVS, Magalhaes ATM, Samuel PA, Hoshin ACH, Porto BL, et al. Expressive vocabulary in children with cochlear implants. Rev CEFAC. 2017;19(3):308-319.

13. Mederake BM. Determining early speech development in children with cochlear implants using the ELFRA-2 parental questionnaire. Int 
J Pediatr Otorhinolaryngol. 2012;76(6):797-801.

14. Tavakoli M, Jalilevand N, Kamali M, Modaresi Y, Zarandy MM. Language sampling for children with and without cochlear implant: MLU, NDW, and NTW. Int $J$ Pediatr Otorhinolaryngol. 2015;79(12):2191-2195.

15. Golestani SD, Jalilevand N, Kamali M. Syntactic abilities in deaf children with cochlear implant and 5- year- old normal-hearing children. Int J Pediatr Otorhinolaryngol. 2018;110: 27-30.

16. Marchman VA, Thal DJ. Words and grammar. In M. Tomasello \& D. I. Slobin (Eds.), beyond nature-nurture: Essays in honor of Elizabeth Bates. Lawrence Erlbaum Associates Publishers. 2005. PP. 141-164.

17. Bates E, Goodman JC. On the inseparability of grammar and the lexicon: Evidence from acquisition, aphasia and real-time processing. Lang Cogn Process. 2010;12(5-6):507-584.

18. Elman JL. An alternative view of the mental lexicon. Trends Cogn Sci. 2004;8(7):301-306.

19. Moyel MJ, Weismer SE, Evans JL, Lindstrom MJ. Longitudinal relationships between lexical and grammatical development in typical and late-talking children. J Speech Lang Hear Res. 2007;50(2):508528.

20. Jung J, Ertmer DJ. Grammatical abilities in young cochlear implant recipients and children with normal hearing matched by vocabulary Size. Am J Speech Lang Pathol. 2018;27(2):751-764.

21. Rahimi M, Sadeghi F, Raseghi S. A comparison of Linguistic Skills between Persian Cochlear Implant and Normal Hearing Children. Iran Rehabil J. 2013;11(1):11-19.

22. Jalilevand N, Kamali M, Modarresi Y, Kazemi Y. The Persian developmental sentence scoring as a clinical measure of morphosyntax in children. Med J Islam Repub Iran. 2016;30(1):980-989.

23. Brown R. A first language: The early stages, Cambridge: Harvard University Press. 1973.

24. Kazemi Y, Derakhshandeh F. Exploring the normal range of scores of Persian speaking children in Robbins-Klee oral/speech motor control protocol. J Rehabilitation. 2007;8(2):50-56.

25. Ling D. Speech and the Hearing Impaired Child: Theory and practice, 2nd ed. Washington, DC: A.G. Alexander Graham Bell Association for the Deaf and Hard of Hearing. 2002.

26. Nematzadeh S, Dadras M, Dastjerdi Kazemi M, Mansoorizadeh M. Persian core vocabulary based on Iranian children, Tehran: Madreseh. 2011.

27. Jalilevand N, Kamali M, Modarresi Y, Kazemi Y. Word order acquisition in Persian speaking children. Iran Rehabil J. 2017;15(2):111-6

28. Beeson PM, Robey RR. Evaluating single-subject treatment research: lessons learned from the aphasia literature. Neuropsychol Rev. 2006;16(4):161-169.

29. Pegoraro-Krook MI, Dutka-Souza JCR. Nasoendoscopy of velopharynx before and during diagnostic therapy. J Appl Oral Sci. 2008;16(3):181-188.

30. Nittrouer S, Sansom E, Rice C, Caldwell-Tarr A. Language structures used by kindergarteners with cochlear implants: relationship to phonological awareness, lexical knowledge and hearing loss. Ear Hear. 2014;35(5):506-518.

31. McGregor KK, Sheng L, Smith B. The precocious two-year-old: Status of the lexicon and links to the grammar. J Child Lang. 